\title{
Circling the drain - contemporary jewellery and the tale of the New Zealand Grayling
}

\section{ART AND SCIENCE WORKING TOGETHER}

By combining art and science, and producing artworks that demystify and inform, it is possible to take scientific research further than science circles alone and allow the narrative to become part of the public vernacular. The intention is to foster interest, to communicate research findings, to raise questions, to become conversation starters, and to be triggers for further research or behavioural change. This interpretation of specialised scientific data allows for the information to be passed on, releasing the research so it can be understood through the objects themselves, with little or no background knowledge necessary.

Contemporary jewellery, as an art form, is well positioned to do this. As a way of connecting people, jewellery can be a powerful means for mobilizing change. ${ }^{1}$ Once attached to a human host, jewellery has great potential for impact. From the origins of humanity, it has played a role of connectivity through symbolic representation. Its logical connection to the body gives the medium potential to speak of important issues within society. ${ }^{2}$

My work examines how jewellery can act as a form of communication and an agent for change. It shows that the framework of contemporary jewellery has great potential to speak of issues within society and the environment.

\section{FRESHWATER EXTINCTIONS}

The archipelago of New Zealand, with its well documented human history and wealth of recent fossils, has the dubious distinction of being one of the best places on earth to research the causes of extinction and the effects of humans on the environment. Worldwide, loss of biodiversity is one of the most alarming threats facing our species, as Edward O Wilson warns us: "[the] quenching of life's exuberance will be more consequential to humanity than all of the present-day global- 
warming, ozone depletion, and pollution combined". ${ }^{3}$ Humans have created a bottleneck of overpopulation and shrinking natural resources. The ecological pressure our species places on the world's plants and animals is intense, and the outcome of such pressure is species extinction on a massive scale.

In recent decades an estimated $20 \%$ of the world's freshwater fish species have become threatened, endangered, or extinct. Extinction rates in fresh water are higher than in terrestrial and marine environments. But New Zealand's only extinct freshwater fish - the grayling, or upokororo - was probably long gone before the current wave of species extinctions.

\section{WHERE DID ALL THE GRAYLINGS GO?}

Once the most common freshwater fish in New Zealand, the grayling appeared to disappear almost overnight. Perhaps, as with the passenger pigeon in North America, its abundance meant that when it vanished people had difficulty comprehending its loss. It is easier to understand when a rare species is lost forever but the sudden disappearance of an abundant species is more difficult to fathom. However, as early as the 1870s, a decline was suspected. There were reports of the fish's disappearance from the Waikato River as early as 1874 and from the Buller district in 1884 . Both areas had previously had very high populations. ${ }^{4}$

Whatever happened to them seems to have happened rapidly. A specimen reportedly caught in the Hokitika in 1923 raised hopes that, after a hiatus, it was returning. But it was not to be. As was noted in 1930 by the Marine Department: "When it is as extinct as the moa-it is rapidly moving in that direction-those who were responsible for the control of New Zealand fisheries will certainly not escape a good deal of scornful criticism." 5 Ironically, by the time legislative protection was granted in 1952, the fish was probably extinct. New Zealand's foremost freshwater fisheries scientist at the time considered grayling as illustrative of an "indifference" with which many of New Zealand's natural resources are treated, ${ }^{6}$ and advised that anyone knowing the location of grayling should keep it a profound secret.

In 1992, the World Conservation Monitoring Centre included grayling on its list of extinct taxa but noted there was still a chance that the fish survived. By 1996, the Red List of Threatened Species, compiled by the International Union for Conservation of Nature (IUCN), categorised the grayling as extinct, the definition of which is "there is no reasonable doubt that the last individual has died". ${ }^{7}$

Recent research undertaken at the University of Auckland's School of Environment has provided a new theory for the extinction - that the grayling was a victim of its own dispersal strategy combined with the effects of environmental modification. Graylings were amphidromous, which means they migrated from river to sea and back at some point in their life cycle. However, unlike salmon, it is believed they did not instinctively return to the place they were born. This meant they often returned to breed in rivers and streams of poor water quality or those inhabited by trout, leading to what ecologists call population "sinks" (whereby once-healthy populations do not reproduce at a rate high enough to counteract mortality, leading to population numbers slowly "sinking"). 
When researchers factor in over-fishing and predation by trout, along with lower breeding rates from poorer quality habitats, models clearly show how the fish became extinct so fast. This work has significant implications for other New Zealand freshwater fish, more than $70 \%$ of which are at risk or under threat of extinction. In particular, there are concerns over whitebait and whether current restrictions are enough to protect them: "Globally freshwater ecosystems are under immense strain, facing habitat loss, invasive species, climate change and over-exploitation, so understanding what happened in the past might allow us to stop extinctions of freshwater biota in future."8

\section{GRAYLING DRAUGHT}

My Grayling Draught exhibition display was made for the purpose of casting shadows, rather than light, to create a feeling of immersion. It was exhibited twice in 2019: at the Dunedin School of Art and at the H D Skinner Annex at Otago Museum. Made up of individual grayling brooches, attached to a frame that slowly turned, the fish slipped in and out of fields of light. This reflected the habit of the species disappearing and reappearing in a ghostly fashion due to its migration and spawning habits.

The individual fish brooches had their own unique markings and patterns, just like the morphological variations seen within the species. Each was designed to be worn as an individual piece, as well as forming a component of the larger artwork. The brooches were etched using the designs drawn by individual school-aged participants in a "Grayling Design Workshop" I conducted during school holidays (Figure 1). As part of the workshop, the participants learnt about the grayling's story and about the importance of preserving our native species.
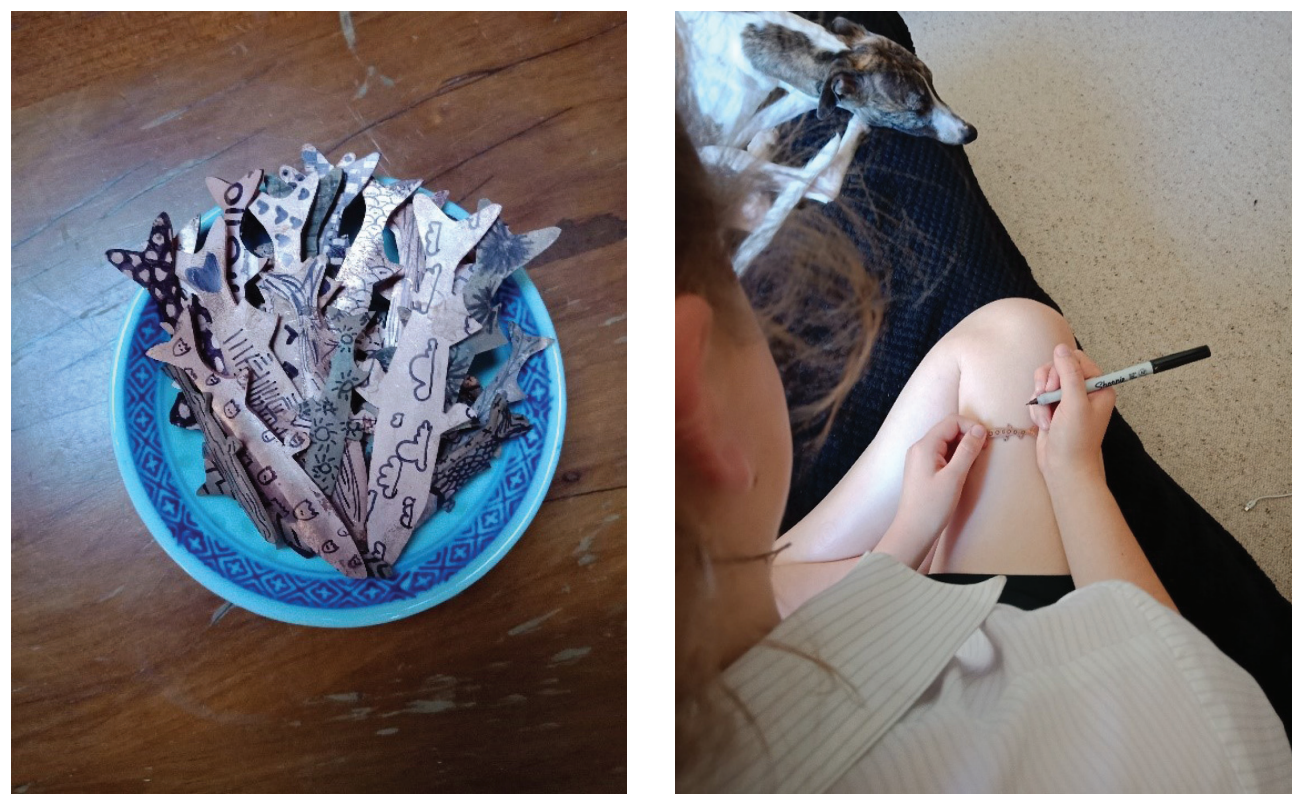

Figure 1. "Grayling Design Workshop" participant decorating the individual fish in preparation for etching. Photograph: M Wilkinson. 

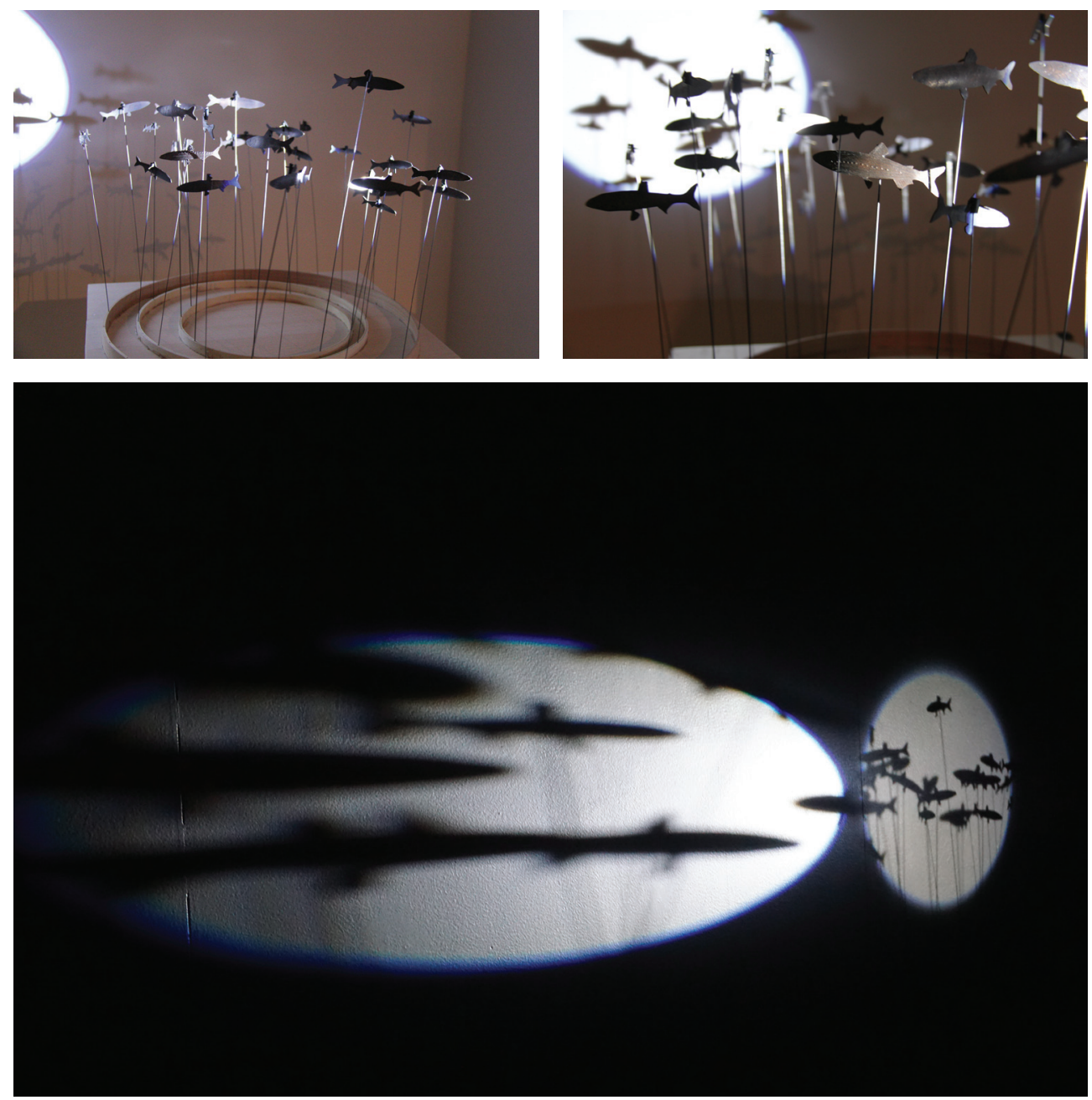

Figure 2. M Wilkinson, Grayling Draught, 2019, exhibition display, Dunedin. Photograph: Pam McKinlay.

When set up in a darkened room, the Grayling Draught created a feeling of sadness and melancholy. As the fish shadows moved through the light, they left an impression of a silent school swimming through space (Figure 2).

The work sought to engage the viewer through contemplation, without offering conclusions. Simply watching the shadows or examining the brooches' tactility was encouraged, leaving viewers to add their own interpretation to the experience. The brooches could then be removed from the turntable, taken away, and worn home by the gallery visitors. In this way, the shoal would slowly decrease until they were all gone. This removal of the objects on display emulated the disappearance of the individuals from the greater gene pool, eventually leaving nothing behind but the display structure itself. These take-away fish become reminders of the gallery experience and the fate of the grayling. 
If someone tells you something, your recall is far more limited than if visuals are included. This recall increases exponentially once someone comes into physical contact with it. It is a wellrecognised phenomenon that as soon as something comes into your hands, by touching it and interacting with it, the recall and understanding of that subject increases. Hands-on experiences for the viewing public allow for active learning; they end up with an experience and anecdote that is more likely to be retained and retold. This information transference, from the maker, the wearer, and the observer, is fundamental to this project, to spread the story of New Zealand's anthropogenic biodiversity loss and to inspire ownership and governance of the future.

Michelle Wilkinson (B.Sc, M.FA) is a contemporary jeweller whose work sits at the cross-roads of art and science. Her current research interests include biodiversity loss and extinction of New Zealand's biota.

1. D Skinner, Contemporary jewellery in perspective (New York, USA: Lark Books, 2013).

2. L den Besten, On Jewellery: A compendium of international contemporary art jewellery (Stuttgart, Germany: Arnoldsche Art Publishers, 2012).

3. Edward O Wilson quoted in A Tennyson, and $\mathrm{P}$ Martinson, Extinct birds of New Zealand (Wellington, New Zealand: Te Papa Press, 2006) 1.

4. K R Allen, "The New Zealand Grayling-A Vanishing Species," Tuatara 2, no. 1, (March 1949) 22-27.

5. C Walrond, "Out of the Frying Pan: Into Oblivion," New Zealand Geographic 75 (2005). https:// www.nzgeo.com/stories/out-of-the-frying-pan-intooblivion/
6. Ibid.

7. D West, B David, and N Ling, Prototroctes oxyrhynchus, The IUCN Red List of Threatened Species (2014) e.T18384A20887241.

8. New Zealand Herald, "What mysterious extinction means for NZ's native fish" (2019) https:// www.nzherald.co.nz/nz/news/article.cfm?c_ $\mathrm{id}=1$ \&objectid=12253225 (assessed 9 March 2020). 